\title{
Collaboration between Russian and U.S. Scientists in Biomedical Research
}

\author{
V. N. Danilenko \\ Vavilov Institute of General Genetics, Russian Academy of Sciences \\ E-mail: valerid@rutenia.ru
}

\begin{abstract}
During the past two decades, tens of thousands of Russian scientists, including leading researchers in the field of biomedicine, have left Russia to work abroad. Some scientists maintained contact with institutes of the Russian Academy of Sciences (RAS) and the Russian Academy of Medical Sciences (RAMS); however, such interactions were usually initiated by the scientist. Recently, there has been a shift in the pattern of international collaboration; the meeting between the representatives of the National Institute of Health (USA) and the Russian Academy of Sciences, held on April 25-26, 2011, in Moscow, is evidence of this change.
\end{abstract}

\section{BACKGROUND}

On July 6, 2009, during the visit by U.S. President B. Obama to Moscow, the establishment of the US-Russia Bilateral Presidential Commission was declared. The move was intended to contribute towards the strengthening of relations (including scientific relations) between Russia and the United States. Eighteen working groups are now at work within the Commission. The Health Working Group headed by Minister of Healthcare and Social Development of the Russian Federation T.A. Golikova and Minister of Health and Human Services of the United States of America $\mathrm{K}$. Sebelius is focused on collaboration in protecting the health of Russian and U.S. residents; and "the entire planet," as is stated in the document. The deputy administrator of the working group is the Deputy Minister of Healthcare and Social Development of the Russian Federation V.I. Skvortsova. In July 2009, a Memorandum of Mutual
Understanding between the Ministry of Health and Human Services of the United States of America and the Ministry of Healthcare and Social Development of the Russian Federation was also signed. In the document, collaboration on healthcare and medical sciences is underlined.

On September 22, 2010, the Foundation for the National Institutes of Health announced the establishment of the US-Russia Medical Science Forum within the framework of the US-Russia Bilateral Presidential Commission in order to facilitate collaboration in the sphere of biomedical research. The Forum was initiated by the National Institutes of Health Fogarty International Center and representatives of the U.S. pharmaceutical business. This private-public partnership aims at advancing collaboration between Russian and U.S. scientists in the field of morbidity control, treatment and prevention, clinical and applied research, the development of new medical technologies, and the design of innovative drugs.

The organizers believe that this meeting should facilitate the establishment of close contacts between Russian and American governmental institutions, as well as between Russian and American scientists. Conferences will be held annually in order to elaborate the strategy of joint scientific research during the forum; the organizers also believe that it will help breach the gap between actual research and the practical implementation of this research. The elaboration of research priorities, formation of joint research projects, including those involving the pharmaceutical business, are among the significant tasks facing the Forum.

In July 2010, representatives of the U.S. National Institute of Health met with the vice-president of the RAS, Academician A.I. Grigoriev. The meeting initiated a scientific dialogue concerning the resumption of collaboration. In October 2010, during a visit by the RAS president, Academician Yu.S.Osipov, to the United States of America, the administration of the U.S. National Institute of Health expressed interest in establishing official collaboration. The working visits of a number of Russian scientists, RAS Academicians V.V. Vlasov and M.V. Ugryumov, RAMS Academicians G.T. Sukhikh and V.A. Tutel'yan, and corresponding member S.V. Netesov to the U.S. National Institute of Health facilitated the elaboration of a platform for collaboration. 


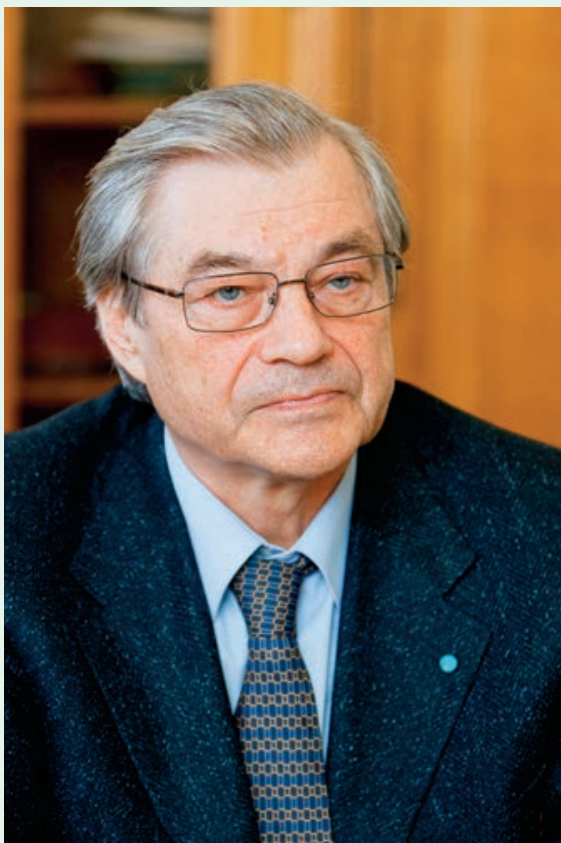

Vice-president of the RAS, Academician A.I. Grigoriev

Much work in this direction has been carried out by the formed Program and Organizational Committees, with outstanding scientists of the RAS, RAMS, and Moscow State University among the members

\section{WORKING CONFERENCE DEVOTED TO FORUM PREPARATION}

The working conference that was held between April 25 and 26, 2011, in Moscow at the Russian Academy of Sciences was an important step towards fostering closer relations between the research communities of the two countries. The major goal of the conference was to prepare the Russian-American Forum on collaboration in the field of biomedical research. The Russian Academy of Sciences, the Ministry of Healthcare and Social Development of the Russian Federation, and the Russian Academy of Medical Sciences were among the organizers on behalf of Russia; the Foundation for National Institutes of Health, the National Institute of
Health, and the Institute of Medicine of the United States National Academy of Sciences, on behalf of the United States of America.

The vice-president of the RAS, Academician A. I.Grigoriev, and the director of the U.S. National Institute of Health Fogarty International Center, Dr. Rodger Glass, were elected as co-chairpersons of the Working Conference.

The deputy chairperson of the Working Group on Healthcare of the US-Russia Bilateral Presidential Commission and Deputy Minister of Healthcare of the Russian Federation V.I. Skvortsova set the major directions of the strategy of interaction between Russian and American scholars within the framework of the Forum. In his report, A.I. Grigoriev highlighted the problems of infrastructural supply for research in Russia, the priorities in biomedical research, and she also emphasized the role of fundamental science as the basis for innovative developments. Dr. Rodger Glass presented a report devoted to the structure of the National Institute of Health, the subject areas of research, and the directions of the bilateral partnership at the initial stage of the Forum's activity.

More than 90 participants sat through the Working Conference; among them were outstanding Russian and U.S. scholars and government officials. A Considerable degree of interest was shown by the business community, including such pharmaceutical and biotechnological companies as Amgen, Amway, Bach Pharma, Becton Dickinson, Bristol-Myers Squibb, Boston Scientific, Coca-Cola, Eli Lilly, GalenBio, Genzyme, Johnson \& Johnson, PepsiCo, and Pfizer.

The following research orientations were selected as topics of discussions at the Conference: fundamental neurology, organism development and childhood pathology; oncology; infections and

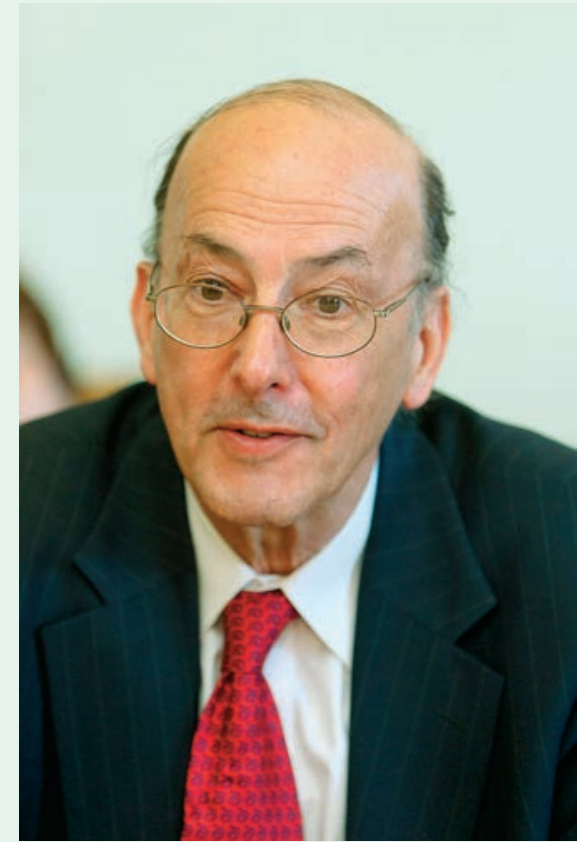

Director of the Fogarty International Center NIH R. Glass

epidemiology; physiology and pathology of the cardiovascular system; healthy lifestyle; and translational medicine. The following scholars made oral reviews of the research carried out in Russia and the United States of America in the selected directions: Academician M.V. Ugryumov (Brain Sciences), RAMS Academician A.A. Baranov (Human development), Academician G.P. Georgiev, and Dr. Ted Trimble (Oncology), RAMS Academician V.V. Zverev and Dr. Robert Fontaine (Infectious Diseases and Epidemiology), Academician V.A. Tkachuk and Dr. Susan Shurin (Cardiovascular Diseases), RAMS Academician V.A. Tutel'yan and Dr. Van Hubbard (Healthy Lifestyle), and RAMS Academician G.P. Sukhikh (Clinical and Translational Studies). A separate section was devoted to business, with 12 reports both on fundamental science and applied clinical and translational studies. The representatives of the business community proposed col- 
laboration and joint participation in the elaboration and promotion of joint projects.

The American delegation visited the Shemyakin and Ovchinnikov Institute of Bioorganic Chemistry, RAS, the Engelhardt Institute of Molecular Biology, RAS, the Institute of Gene Biology, RAS, the Vavilov Institute of General Genetics, RAS, Lomonosov Moscow State University (Faculty of Fundamental Medicine), Blokhin Russian Cancer Research Center, RAMS, Cardiology Research Center, Ministry of Healthcare and Social Development, the Child Health Research Center, RAMS, and the Nutrition Research Center, RAMS. During these meetings, the participants discussed the specific problems of the scientific partnership.

To conclude, the co-chairpersons of the Conference formulated recommendations for the development of the Forum's structure and determined the most important work stages.

The initial stage of collaboration is meant to determine priority projects that are of mutual interest to leading research institutions and groups in both countries, and to involve partners from non-governmental organizations and the private sector. Provisions have been made for other governmental institutions and non-governmental organizations to join the collaboration, including the Foundation for the National Institutes of Health, the U.S. Agency for International Development, and private sector organizations.

The formation of a bilateral working committee which will be made up of representatives of organizations on both the Russian and American sides, as well as business, has been scheduled. The Committee will elaborate the criteria for selecting projects, partners, the terms of project financing, and will ensure that the deadline for the prepara- tion of the Forum conference in November 2011 in Moscow is met.

\section{SIGNING THE RAS-NIH MEMORANDUM}

On April 26, 2011, in Moscow, in the old residence of the RAS Presidium, the scientific collaboration already underway was officially formalized through the signing of the memorandum on collaboration in the sphere of fundamental biomedical research between the Russian Academy of Sciences and the U.S. National Institute of Health.

On the Russian part, the following personalities participated in the signing: vice-president of the RAS, Academician A.I. Grigoriev, vice-president of the RAS, Academician A.F. Andreev; the Counsellor to the president of the RAS in foreign economic activity, Academician M.V. Ugryumov; Deputy Head of the Board for Foreign Relations of the RAS, V.V. Shapovalenko; Academic Secretary of the Council under the RAS Presidium "Medical Engineering, Technology, and Pharmaceutics," Professor V.N. Danilenko, and the representative of the Department of Foreign

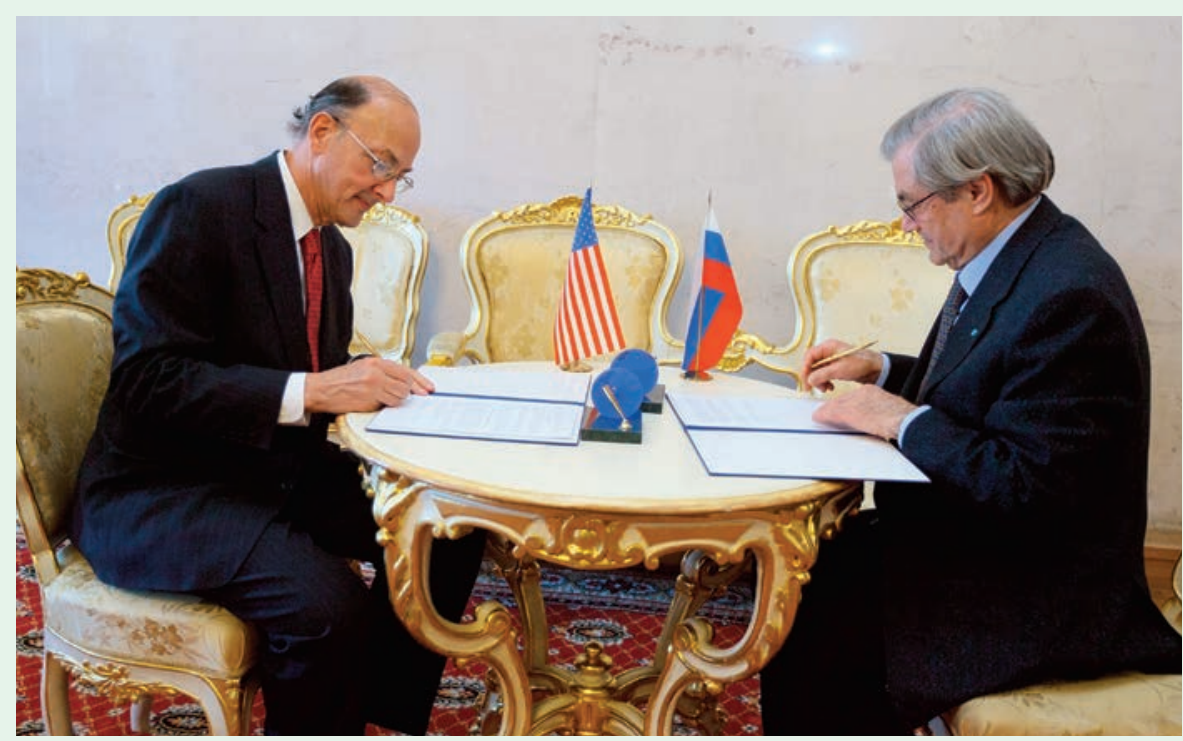

Signing the RAS-NIH Memorandum
Relations of the RAS, Yu.K. Shiyan.

On the U.S. side, the following personalities participated in the signing of the Memorandum: Director of the Fogarty International Center R. Glass, President of the Office of Global Health of the Ministry of Health and Human Services of the United States of America N. Dolaire, President of the Institute of Medicine of the U.S. National Academy of Sciences H. Feinberg, Director of the National Heart, Lungs, and Blood Institute S. Shurin, Director of the Foundation for the U.S. National Institute of Health S. Campbell, Professor at the Medicine Institute G. Cassell, Deputy Head of the U.S. Mission to Russia M. Mitman, and Coordinator of the Fogarti International Center M. Levintova.

After a 12-year gap, this document made public the official collaboration between the two largest research organizations in Russia and the United States of America in the field of biomedical studies.

The scope of the priorities in the collaboration had been outlined at the initial stage. They include on- 
cologic, cardiovascular, neurologic and infectious diseases; innovation pharmaceutics, translational research, bio-safety, and the health of large population groups (megapolises, stress situations, and geographic features). It is assumed that the priorities in the collaboration could be adjusted if necessary.

\section{THE FORUM SCHEDULED FOR NOVEMBER 2011}

The Conference within the framework of the U.S.-Russia Scientific Forum for Biomedical and Behavioral Research will be held in Moscow in November of 2011. The organizing committee of the Forum is currently being formed. It will include representatives of the Russian Academy of Sciences, the Ministry of Healthcare and Social Development of the Russian Federation, the Russian Academy of Medical Sci- ences, the U.S. National Institute of Health, the Institute of Medicine of the U.S. National Academy of Sciences, and private companies.

The Foundation for NIH has begun accepting applications from organizations and companies for participation in the Forum. The terms of participation and the application forms can be downloaded at http:// www.medtechpharm-ras.ru (in Russian) and http://www.fnih.org/ work/programs-development/usrussia-scientific-forum (in English). The most promising projects and proposals will be selected to participate in the Forum. Proposals for the Forum may comprise applications for scientific conferences, researchers exchange programs, research projects, educational programs, and professional-development courses.

The platform for partner collaboration between Russian and U.S. scientists has been prepared; however, given the immutable importance of the human factor, leaders willing to and capable of organizing such collaboration are being actively sought. As mentioned by many participants at the Conference, a great contribution to the organization of the collaboration was made by Professor Gail Cassell, who has devoted more than 10 years to joint U.S. - Russian research in the field of the study and treatment of tuberculosis. It is of considerable importance that the world's largest pharmaceutical companies are showing interest in joint Russian-American projects. Medico-biological science in any country can develop only if there is demand from the government, industry, and medicine aimed at ensuring the health of populations. 